\title{
LA RESPONSABILIDAD DEL CONTADOR PÚBLICO EN EMPRESAS IMPUTADAS POR DELITOS TIPIFICADOS EN LA LEY PENAL TRIBUTARIA
}

\author{
ROSSANA GRECO \\ OSCAR NEDEL
}

FACULTAD DE CIENCIAS ECONÓMICAS DE LA UNIVERSIDAD NACIONAL DEL NORDESTE

ARGENTINA 


\title{
1. RESUMEN
}

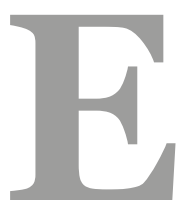

l objeto de estudio del presente trabajo es la responsabilidad del contador público en su actuación como auditor externo de estados contables, en el marco de la ley penal tributaria y previsional, teniendo en cuenta la modificación de la ley 24.769 introducida por la ley 26.735 (BO: 28.12.2011) que incorpora el concepto de responsabilidad empresarial, aceptando como sujeto no solo a la persona física, sino que también a la persona jurídica. La metodología utilizada se basó en la revisión doctrinaria, jurisprudencial y de normativa técnica, haciendo especial detención en el análisis de una causa judicial de resonancia e impacto en el ámbito profesional "K.,S. y otro s/recurso de casación" (causa judicial No 9950) de la Sala II- de la Cámara Nacional de Casación Penal de fecha o7 de diciembre de 2009. Se concluye que existe el potencial riesgo de que el auditor de estados contables quede involucrado en la figura de partícipe necesario del delito de evasión fiscal, junto a los socios, incluso con una pena mayor que los directivos del "sujeto" demandado o condenado. Se resaltó, también, la importancia que el profesional sea cuidadoso en su actuación y documente su trabajo profesional con papeles de trabajo adecuados, que le permitirán minimizar y justificar su actuación, en el marco de las responsabilidades que le caben, pretendiendo con ello su utilización como medios de prueba en potenciales acciones de responsabilidad. Resultará prudente que todos los profesionales, en el marco de su ejercicio y desempeño profesional actúen de modo y manera idónea, ética y responsable. Para ello deberán conocer la normativa vigente, los alcances de su actuación y la pertinente instrumentación de aquellas herramientas que le resultarán útiles para salvaguardar su patrimonio y garantizar su idoneidad.

Palabras Clave: auditor externo, partícipe necesario, evasión fiscal.

\begin{abstract}
The object of study of the present work is the responsibility of the public accountant in its performance like external auditor of countable states, within the framework of the tributary and previsional penal law, considering the modification of law 24,769 introduced by the law 26,735 (BO: 28.12.2011) that it incorporates the concept of enterprise responsibility, accepting like subject not only to the physical person, but that also to the legal person. The used methodology was based on the doctrinal, jurisprudencial review and of technical norm, making special halting in the analysis of a judicial cause of resonance and impact in professional scope "K., S. and another one as resourse of abrogation" (judicial cause $\mathrm{N}^{\circ}$ 9950) of Room II of the National Camera of Penal abrogation of date 07 of december of 2009. One concludes that the potential risk of which the auditor of countable states is involved in the contributor figure of necessary participant in the crime of tax evasion, next to the partners,
\end{abstract}


even with a pain greater than the directors of the demanded or condemned subject. It stood out, also, importance that the professional is careful in their performance and documents their professional work with suitable papers of work, that will allow him within the framework to diminish and to justify their performance of the responsibilities that fit to him, trying with it their use like means of test in potential actions for damages. It will be prudent that all the professionals, within the framework of their exercise and professional performance act of way and suitable, ethical and responsible way. For it they will have to know the norm effective, the reaches of its performance and the pertinent instrumentation of those tools that will turn out to him useful to safeguard their patrimony and to guarantee their suitability.

Keywords: external auditor, necessary accomplice, fiscal evasion.

\section{INTRODUCCIÓN}

La voz responsabilidad proviene del latín respondere que significa prometer, merecer, pagar. Así entendemos por responsabilidad a la obligación de reparar un daño causado a otro, por un acto contrario al orden jurídico, convirtiéndose en un deber de resarcimiento. Esta obligación nace del incumplimiento o la violación de un deber jurídico. "El deber jurídico es la conducta que, de acuerdo con un orden jurídico, se debe hacer u omitir; quien la debe hacer u omitir es el sujeto obligado" (Trigo Represas y López Mesa, 2004, p.16).

La responsabilidad es el resultado de la acción por la cual el hombre expresa su comportamiento frente a un deber u obligación; surge en la fase de la violación de la norma u obligación, y consiste en el deber de soportar las consecuencias desagradables a que se ve expuesto el autor de la transgresión, traducidas en las medidas que imponga la autoridad encargada de velar por la observancia del precepto (Trigo Represas y López Mesa, 2004, p.2).

Dentro de estos vocablos, nos centraremos en la obligación legal, puesto que la obligación moral -implícita en la anterior- se enfatiza en la responsabilidad disciplinaria, y dará lugar a una sanción con respaldo en las reglas amparadas en el derecho normativo que rige a una profesión.

Conforme la teoría general de la responsabilidad, ésta se traduce en el deber de reparar el daño causado a otro que tiene todo aquel, que por su conducta antijurídica, ha ocasionado el daño. Dicha conducta origina una sanción que puede tener naturaleza de tipo represivo o resarcitorio.

En las sanciones represivas no existe equivalencia material entre la infracción y el daño causado, por lo que éstas son típicas del derecho penal común o económico, dentro de la órbita de la responsabilidad penal. 
En las sanciones resarcitorias sí poseen un principio de equivalencia entre el daño y la indemnización con la que se resarce y son propias del derecho civil y comercial, encuadrándose en la órbita de la responsabilidad civil.

El código de ética unificado de los profesionales en ciencias económicas de la República Argentina -artículo $10^{\circ}$ - expresa “...La responsabilidad por la actuación de los profesionales es personal e indelegable, siempre debe dar respuesta de sus actos. En los asuntos que requieran la actuación de colaboradores, deben asegurar su intervención y supervisión personal mediante la aplicación de normas y procedimientos técnicos adecuados a cada caso. No deben firmar documentación relacionada con la actuación profesional que no haya sido preparada, analizada o revisada personalmente o bajo su directa supervisión, dejando constancia en que carácter la suscriben". Así, la mayor jerarquía en el desempeño de sus funciones y la exigencia de estudios de nivel de grado y posgrado, suponen en el profesional una capacidad distinta para analizar, comprender y actuar con respecto a temas que afectan o involucran a terceros. En consecuencia, se les asigna responsabilidades de tipo penal, civil, disciplinaria y de otra índole, que se irán abordando, de modo simple y sin exagerada amplitud, solamente en los aspectos relevantes relacionados con el tema central.

Cabe recordar la manda del artículo $18^{\circ}$ de la Constitución Nacional que establece “.... ningún habitante de la nación puede ser penado sin juicio previo fundado en ley anterior al hecho del proceso", con lo que aparece así sancionado el derecho penal material plasmado en un conjunto de normas que determinan los comportamientos punibles y las sanciones que se aplican, y el formal referido a los medios que permiten la realización del derecho penal. A este último también se lo conoce como derecho procesal penal, que constituye el marco en el que se han de cumplir las garantías fundamentales del estado de derecho en materia penal instituyéndose fundamentalmente un órgano de justicia para resolver las distintas controversias que en forma exclusiva pertenece al Estado.

En el presente trabajo se pretende formular un análisis de las implicancias del desempeño del contador público en el rol esencial de auditor externo de estados contables del ente bajo el amparo de la ley penal tributaria y previsional (Ley 24.769 y sus modificatorias).

Se trata así de exponer, inicialmente, algunas de las principales características relacionadas con el ejercicio profesional en el área de auditoria externa de estados contables, conforme las prácticas habituales y de acuerdo a las normas contables profesionales vigentes.

En una instancia posterior, se describen los aspectos más destacados de la responsabilidad penal derivada de la ley penal tributaria, a través del análisis crítico de la causa judicial $N^{\circ} 9950$ “K.,S. y otro s/recurso de casación” de la sala II de la Cámara Nacional de Casación Penal de fecha 07 de diciembre de 2009, en la que el auditor de los estados contables de una empresa imputada de evasión fiscal, quedó inculpado como partícipe necesario de ese delito. Es dable destacar la trascendencia de este caso, porque origina precedente en la jurisprudencia argentina.

El objetivo del análisis de dicha causa judicial es realizar una revisión del fallo, a los efectos de destacar aspectos sobresalientes de los criterios y alcances de la interpretación 
técnica, tenidos en cuenta por los magistrados para fundamentarlo, en lo que hace a la participación necesaria del contador-auditor en la comisión del delito de evasión.

Sin ánimo de dar como acabado el tema, se espera dar luz -a través de situaciones concretas y jurisprudencia- al tema abordado con la finalidad de orientar las acciones de buenas prácticas, contribuyendo así a una mayor concientización sobre algunos aspectos relacionados con el desempeño del contador público en un complejo escenario de actuación profesional.

\section{EL PROFESIONAL EN CIENCIAS ECONÓMICAS}

El contador público, cuando desarrolla su actividad en el ámbito de las pequeñas y medianas empresas -PyMES- actúa y presta diferentes servicios profesionales -liquidación de remuneraciones, impuestos nacionales y provinciales, formulación y proyección presupuestaria, determinación de costos, análisis de operaciones financieras- $\mathrm{y}$ un asesoramiento permanente en todos estos temas; habitualmente presta, también, el servicio relacionado con el procesamiento de la documentación y confección de estados contables, añadiendo a éstos la auditoria de dichos estados.

En empresas de mayor complejidad, la auditoría, generalmente, se encuentra a cargo de un equipo de auditores externos contratados especialmente para ese fin. En ambas situaciones, conforme las normas de auditoria vigentes, el profesional debe tener independencia respecto a la información que audita. En la práctica, sería conveniente revisar si esta independencia no se encuentra comprometida, cuando se presta dicho servicio profesional en las PyMES, aspecto que podríamos extendernos pero no es el objeto de este trabajo. Se han escrito varias páginas sobre esta temática, y si bien sabemos que, en la actualidad, la mayoría de las sociedades deben presentar sus estados contables auditados (Gil,2008), sería conveniente que en las PyMES se morigerara y hasta evitara esta exigencia, atendiendo a las características propias que las distinguen (concentración de funciones gerenciales y operativas, reducida cantidad de personal, sistema de información deficiente, informalidad en las comunicaciones, achatamiento de la pirámide organizacional, falta de una adecuada estructura de control interno, etc.) que en muchos casos, hasta podrían afectar su condición de auditabilidad.

En este contexto, un gran número de contadores públicos, tiene la documentación de sus clientes en sus estudios para su carga y procesamiento, la liquidación de impuestos y confección de las declaraciones juradas, hasta llegar incluso a su presentación desde los equipos informáticos situados en su Estudio a los distintos organismos de recaudación y control (AFIP, ATP, DGR, etc.), con el agravante que para materializar dicha actividad y gestión, necesita las claves de acceso de sus clientes (contribuyentes...), estableciendo y acentuando la íntima relación cliente-profesional.

De la forma descripta, aparece el contador público, como materialmente responsable por los servicios profesionales, de su contenido y de las consecuencias, mientras el contribuyente (cliente...) no tiene participación ni conocimiento de aquellos temas que poseen directa relación de su actividad (referidos a la faz impositiva, previsional, laboral,....). 


\section{EL AUDITOR EXTERNO DE ESTADOS CONTABLES}

\subsection{Causa judicial ilustrativa.}

En el punto anterior referimos a la actual modalidad en la que, generalmente, desarrolla las tareas el contador público y los ámbitos en los que se desempeña, particularizando en su actuación como auditor externo de estados contables (Ley 20488/73. Art. 13. Inc. $1^{0}$ y 11). A los efectos de ilustrar el complejo contexto actual en el que dicho profesional debe desempeñarse analizaremos -más adelante algunos aspectos de la causa judicial $N^{\circ} 9950$ "K.,S. y otro s/recurso de casación" de la sala II- de la Cámara Nacional de Casación Penal de fecha o7 de diciembre de 2009, en la que la empresa entrerriana "K... Automotores SA", fue imputada por el delito de evasión fiscal ${ }^{1}$, y su contador-auditor externo J.R.B. fue considerado partícipe primario penalmente responsable de esa maniobra, con sentencia dictada en el año 2008 por el tribunal oral en lo Criminal Federal de Paraná, y la Cámara Nacional de Casación Penal confirmó las condenas. El recurso extraordinario federal impetrado ante la Corte Suprema de Justicia de la Nación por la defensa del profesional, fue denegado como así también la queja por recurso denegado.

Cabe agregar que el recurso de casación es "el que se interpone ante el tribunal supremo contra fallos definitivos o laudos, en los cuales se suponen vulneradas leyes o doctrina legal, o quebranto de alguna garantía fundamental del procedimiento" (Valleta, 2006, p.688). Este recurso extraordinario puede ser interpuesto por el vencido, con el objeto de anular una sentencia judicial considerada incorrecta por una inadecuada interpretación o mala aplicación de la ley, o porque fue dictada sin cumplir con el procedimiento judicial que correspondía. En Argentina, este fallo le corresponde a la Cámara Nacional de Casación y no a la Corte Suprema de Justicia -órgano de mayor jerarquía- como habitualmente ocurre en otros países.

\subsection{Consecuencias de la actuación del auditor externo de estados contables en un contexto normativo complejo.}

El auditor de estados contables cumple una función social, coadyuvando a los usuarios a evaluar la credibilidad de la información contenida en los respectivos informes contables, preparados y emitidos por la empresa. Su tarea consiste en aplicar procedimientos de auditoria con la finalidad de expresar una opinión respecto a la razonabilidad o no del contenido de dichos informes basado en las evidencias obtenidas, o de abstenerse de opinar si no pudiera obtenerlas en forma suficiente.

El informe del auditor es el resultado principal de su trabajo, siendo el documento que trasciende a terceros, constituyendo por ende el elemento clave para evaluar su actuación pública (...). Representa el producto terminado cuando el

\footnotetext{
${ }^{1}$ Ley 26.735 (BO: 28-12-2011) modificatoria de la Ley 24.769 incorpora el concepto de "Responsabilidad Empresaria" aceptando como
} sujeto a la "persona jurídica". 
contador público ejerce la actividad de auditor independiente (Casal, A. en Mosset Iturraspe y González Zünd, 2014, pág.214).

La responsabilidad del auditor, deriva básicamente de las normas que regulan el ejercicio profesional (Ley 20.488), del código de ética unificado, de la resolución técnica 37/13 de la Federación Argentina de Consejos Profesionales en Ciencias Económicas (FACPCE), entre otra normativa profesional, complementada por la existencia de exigencias legales establecidas por el derecho positivo vigente (código civil, ley de sociedades comerciales, código penal y sus leyes complementarias y modificatorias).

Si continuamos focalizando el tema en estudio, será dable acotar el análisis de la responsabilidad del auditor al ámbito penal, puntualmente, en el marco de la ley penal tributaria; además de la jurisprudencia relacionada con la aplicación de esta normativa legal, quien ubicó al contador-auditor en la obligación de responder, no solamente con la privación de su libertad, sino también, con la inhabilitación en su matrícula para el ejercicio de su profesión.

De allí que consideramos anticipadamente nuestra opinión expresando que la responsabilidad que asume el auditor con la emisión de sus Informes tiene una connotación diferente, desde que el profesional emisor, podría ser imputado en la figura de partícipe necesario del delito de evasión fiscal previsto en la ley penal tributaria y previsional.

La FACPCE emitió, en el año 2004, dos documentos en respuesta a esta situación, luego de un análisis del contexto en que los matriculados debían ejercer la profesión, identificando una gran carga de responsabilidades y presiones legales (por fallos judiciales que reflejaban cierta confusión con las tareas profesionales), llegando a equipararlas con las funciones propias de la dirección del sujeto jurídico o ente.

Estos documentos fueron difundidos con los siguientes títulos:

1. Funciones y responsabilidades del contador público ${ }^{2}$, con el objetivo de difundir, entre los matriculados de todo el país, el poder judicial, los organismos de recaudación y de control, y los medios de comunicación, la definición de las diferentes funciones que puede asumir dicho profesional en el ejercicio de su actividad, y así fijar las responsabilidades que le caben con orden a la legislación civil, comercial y penal vigentes, las administrativas especiales (policía del estado, sistema financiero, seguros, entre otras) y las éticas, y;

2. Responsabilidad del contador público que actúa como auditor, síndico societario, consultor o asesor técnico impositivo o provisional, liquidador impositi-

\footnotetext{
${ }^{2}$ Resolución conjunta de la Federación Argentina de Consejos Profesionales de Ciencias Económicas y de la Federación Argentina de
} Graduados en Ciencias Económicas. Buenos Aires, 15 de marzo de 2004. 
vo, o que presta servicios de tercerización (llevar la contabilidad, liquidación de sueldos y otros). Recomendaciones (Memorando de secretaría técnica o-1-), consistente en una guía para definir adecuadamente la responsabilidad del contador público cuando presta dichos servicios, en la relación con sus clientes.

En dichos instrumentos, la FACPCE realiza recomendaciones generales aplicables a los distintos roles profesionales que, en el marco del artículo 13 de la Ley 20.488 de ejercicio profesional, deberían permitirle al contador público, encuadrar el servicio a prestar y consecuentemente delimitar y comunicar al cliente adecuadamente la responsabilidad que asume, en todos y cada uno de dichos servicios, a saber:

* Emitir una propuesta de prestación de servicios profesionales (detallando los tipos de prestaciones, la metodología y los procedimientos que se aplicarán, el producto final, las limitaciones y alcances de la participación como profesional y la estimación de los honorarios) además de una carta de contratación debidamente aceptada por el cliente, que detallen los objetivos de los servicios ofrecidos y acordados, su alcance, las responsabilidades asumidas por las partes, la fecha estimada de finalización de las tareas, honorarios y forma de pago. El memorando adjunta un modelo de propuesta de servicios profesionales como anexo I y un modelo de carta de contratación como anexo II.

* Recibir una carta de representación del cliente.

* Reunir y conservar los papeles de trabajo que evidencien el asesoramiento o servicio prestado.

Por otra parte y, a continuación de estas recomendaciones, aclara que el hecho que no existan estos documentos, no implica un agravamiento de la responsabilidad del profesional, sino que por su ausencia le podría resultar más difícil probar los límites de su servicio y en consecuencia su responsabilidad en caso de algún conflicto. Ambos documentos, leídos en forma conjunta, comprenden sugerencias para que los profesionales reduzcan la posibilidad de asumir riesgos mayores que los que correspondan por el correcto ejercicio de su actividad profesional.

En el año 2005, como consecuencia de un fallo judicial en el que se imputó su conducta en "dolo eventual" a un contador-auditor de estados contables, la FACPCE emitió un nuevo documento, en el que expresó su opinión sobre los balances que posibilitan la evasión tributaria bajo el título de "La responsabilidad penal del auditor por dolo eventual. Advertencia de la FACPCE a los profesionales auditores”. En ese documento la Federación fijó su postura respecto de la figura del dolo eventual, entendiendo que se configura cuando el sujeto puede conocer el resultado de probable producción y, aunque no quiera producirlo, sigue actuando, 
admitiendo así su eventual realización. Al respecto argumentó que “...la actividad de los profesionales auditores debe considerarse incompatible con el dolo eventual”, y que la responsabilidad del contador público, solo existe a título de dolo directo, o no existe. Si existe debe probarse su conducta disvaliosa.

Admite que al auditor se le impute una responsabilidad a titulo de "dolo directo", una vez probada su participación en el ilícito, pero no admite su imputación a título de dolo eventual, porque implica juzgarlo por lo que es y no por lo que hace, en otras palabras, se lo estaría juzgando, por portación de título.

Ante esto, sugiere adoptar los recaudos necesarios y tendientes a deslindar responsabilidad ante el servicio profesional de auditoría de estados contables, cuyos administradores resulten pasibles de ser juzgados y acusados por la comisión de delitos tributarios.

\subsubsection{Consecuencias penales del auditor externo de estados contables de empresas que pudieran quedar incursas en delitos tipificados en la ley penal tributaria y previsional. Revisión de fallo judicial.}

Han transcurrido ya algunos años desde de la emisión de los antes mencionados documentos de la FACPCE y, a pesar de ello, aún estamos en presencia de causas judiciales, entre las que se encuentra la mencionada anteriormente y que procederemos a su análisis, que conmocionan a la comunidad profesional, especialmente entre los contadores que actúan como auditores de estados contables en empresas que son imputadas del delito de evasión fiscal en el marco de la ley penal tributaria.

Si bien existen otras causas judiciales, tomaremos como referencia para su análisis a la causa judicial $N^{\circ} 9950$ “K.,S. y otro s/recurso de casación” de la sala II de la Cámara nacional de casación penal, ya descripta anteriormente. Recordemos que la empresa entrerriana "K... Automotores SA", fue imputada por el delito de evasión fiscal ${ }^{3}$, y su contador-auditor externo J.R.B. fue considerado partícipe primario penalmente responsable de esa maniobra.

Frente a este severo fallo respecto al juzgamiento de la conducta desplegada por un profesional en ciencias económicas -contador público-, que entre los servicios profesionales, también se desempeñaba como auditor externo, analizaremos algunos aspectos de dicho fallo a través del examen de algunas de las expresiones utilizadas por los jueces intervinientes.

Este trabajo no tiene intención alguna en juzgar ni criticar a las partes intervinientes en la causa judicial antes indicada. Su análisis se realiza con la principal finalidad de exponer aspectos relevantes que permitan salvaguardar la responsabilidad cuando el contador desarrolle su ejercicio profesional, siempre dentro de un marco de ejercicio ético de la profesión.

${ }^{3}$ Ley 26.735 (BO: 28-12-2011) modificatoria de la Ley 24.769 incorpora el concepto de "Responsabili-dad Empresaria" aceptando como sujeto a la "persona jurídica". Ampliaremos mas adelante sobre éste tema. 
A dicho efecto, primero transcribimos algunos párrafos que interesan, así:

* El Tribunal oral en lo Criminal Federal de Paraná, Entre Ríos, resolvió:

** “...Condenar a S.K. por considerarlo autor penalmente responsable del delito de evasión simple del impuesto a las ganancias del año 1998 y del Impuesto al valor agregado de los períodos de febrero a diciembre del año 1999 y de enero a mayo del año 200o, a la pena de dos años de prisión de ejecución condicional y el $50 \%$ de las costas... ${ }^{\prime \prime}$.

** “...Condenar al Contador J.R.B. -por considerarlo partícipe primario penalmente responsable del delito de evasión simple por los impuestos y períodos antes mencionados- a la pena de dos años de prisión de ejecución condicional, el $50 \%$ de las costas e inhabilitación especial por el doble de tiempo de la condena para ejercer la profesión...5". Resaltamos el hecho que en la condena, la pena para el profesional fue mayor que la del propio autor del hecho.

** "...Se imputó al contador J.R.B. la comisión del delito previsto en el art. 15 de la ley 24.769, toda vez que, en su condición de profesional de las ciencias económicas y contador externo de la empresa 'K. S.A.', auditó y certificó el estado contable correspondiente al período o1/01/98 al 31/12/98 de dicha firma, contribuyendo y facilitando así por ese período y respecto del impuesto a las ganancias, la comisión del delito de evasión fiscal imputado conjuntamente a ambos" (folio 997 - expediente de la causa).

La Administración Federal de Ingresos Públicos (AFIP) -parte querellante en este juiciodeterminó una diferencia de más de un millón de pesos en perjuicio del erario público, porque la empresa declaró menos ingresos de los que correspondía y computó más crédito fiscal según los registros materializados en los libros IVA ventas e IVA compras, respectivamente.

El tribunal, por unanimidad, entendió que el hecho estaba suficientemente demostrado, tanto en relación al IVA por los períodos 02/99 al 12/99 por un monto de $\$ 306.191,10$ y por los períodos 01/oo al 05/oo por la suma de $\$ 130.317,01$; como respecto al impuesto a las ganancias, período 1998 por la suma de $\$ 580.969,46^{6}$.

\footnotetext{
${ }^{4}$ Pena prevista en los artículos. 1ㅇ y 14 de la ley 24.769, 26 del Código Penal y 531 del Código Procesal Penal de la Nación.

${ }^{5}$ Penas previstas en el artículo 10 y 15 inciso "a" de la ley 24.769, artículo 26 del Código Penal y 531 del Código Procesal Penal de la Nación.

${ }^{6}$ Ley 26.735 Artículo 1 se modificaron los montos en exceso para evasión simple, estableciéndose en $\$ 400.000$,=mientras que la Ley 24.769 contemplaba el límite de $\$ 100.000,=$ para el mismo concepto.
} 
En el Libro de IVA compras se detectaron registros de créditos fiscales menores a los consignados en las declaraciones Juradas de los períodos antes mencionados, razón por la que la AFIP impugnó dichos créditos. Analizadas las operaciones entre la empresa y su principal proveedor de automóviles (General Motors Argentina SA) y, comparado con lo informado por ambas firmas, la AFIP advirtió que la empresa había omitido de registrar facturas en el libro IVA ventas, varias notas de crédito no fueron registradas y otras fueron registradas como facturas de compra (originando una doble registración del crédito fiscal). En el expediente ${ }^{7}$ de la causa se detallan los fundamentos que los jueces utilizaron como basamento para dictar las condenas, tanto para el responsable (sujeto jurídico), como para el profesional en ciencias económicas en calidad de partícipe en el delito tipificado como evasión fiscal, habiendo considerado que el profesional por su formación y conocimientos se torna en partícipe (aporte esencial) para que el delito pueda materializarse. Algunos de estos fundamentos se transcriben y analizan más adelante, luego de una breve revisión de algunos conceptos que optimizarán su comprensión.

\section{REVISIÓN CONCEPTUAL}

Sin ánimo de ampliar innecesariamente ni extender sin razón la base de nuestro trabajo, resulta prudente formular una mínima revisión conceptual que, en muchos casos, permitirá entender el alcance de algunas expresiones que sobresalen del marco literal que tenemos bajo análisis, como así también comprender adecuadamente los apartados subsiguientes que profundizan el estudio de la causa judicial.

\section{1.- Evasión (delito de...).}

La evasión se logra mediante conductas fraudulentas y omisivas por las cuales, para ser punible en ésta figura, la conducta debe ser acompañada de fraude el cual, se configura cuando el resultado se logra utilizando las conductas que la norma describe. La evasión posee dos elementos que deben presentarse y que son, el ardid o engaño y el perjuicio patrimonial, debiendo producirse de modo simultáneo y manifestarse en daño.

- El ardid o engaño, es el despliegue de artificios o maniobras disimuladores de la realidad, que debe ser idóneo; es decir, debe tener la aptitud suficiente para burlar al fisco.

\footnotetext{
${ }^{7}$ Registro № 15654 de la Sala II de la Cámara Nacional de Casación Penal -en el que constan las expresiones de los jueces que fueron designados para resolver el recurso interpuesto por los acusados para fundamentar sus votos referentes a la condena incluida en los folios 996 a 1030 de la Causa- refleja el pensamiento o idea que tienen los jueces sobre las tareas que realiza el Contador y su influencia directa para la ocurrencia de estos delitos tributarios a través de sus aportes técnicos.
} 
- El perjuicio patrimonial que debe presentarse de modo simultáneo, y se configura al no ingresarse un monto a las arcas estatales, siendo esto condición objetiva de punibilidad.

\subsection{Delito de evasión simple de impuestos.}

Se configura por la acción u omisión, con la condición objetiva de punibilidad y a partir de un monto determinado por impuesto.

\subsection{El bien jurídico protegido.}

Los delitos contra la hacienda pública (arcas estatales o erario público) son delitos socio económicos que protegen un bien jurídico difuso del que son titulares todos los integrantes de la sociedad. El bien jurídico tutelado o protegido es el patrimonio de la administración pública, es decir cualquiera de los poderes del estado. Consecuentemente, se protege al erario público, que se ve afectado por la evasión fiscal, ya que el Estado no puede cumplir con sus fines como corresponde porque su capacidad se ve disminuida por el delito. El delito fiscal, no solo entraña una disminución del valor económico en el erario público, sino que afecta a toda una política económica social que incide sobre el ahorro, la inversión, la distribución de la renta nacional, etc.

\subsection{La evasión agravada.}

Está tipificada, enunciada y comprendida en el artículo $2^{\circ}$ de la ley 24.769, entendiéndola “...como la maniobra utilizada que se halla acompañada por el despliegue de un ardid o engaño idóneo para inducir el error al fisco...”y además agravada por los medios utilizados, el monto evadido y la utilización de las personas interpuestas para la ocultación de la identidad del verdadero sujeto obligado. Debemos tener en cuenta que éste artículo también fue modificado por la Ley 26.735, estableciéndose en consecuencia ajustes en los importes anteriormente contemplados al establecerse: "Artículo 2: Sustituyese el artículo 2 de la ley 24.769 y sus modificaciones, por el siguiente: Artículo 2: La pena será de tres (3) años y seis (6) meses a nueve (9) años de prisión, cuando en el caso del artículo 1 se verificare cualquiera de los siguientes supuestos: a) Si el monto evadido superare la suma de cuatro millones de pesos (\$ 4.000.00o); b) Si hubieren intervenido persona o personas interpuestas para ocultar la identidad del verdadero sujeto obligado y el monto evadido superare la suma de ocho-cientos mil pesos (\$ 800.00o); c) Si el obligado utilizare fraudulentamente exenciones, desgravaciones, diferimientos, liberaciones, reducciones o cualquier otro tipo de beneficios fiscales, y el monto evadido por tal concepto superare la suma de ochocientos mil pesos (\$ 800.0oo); y d) Si hubiere mediado la utilización total o parcial de facturas o cualquier otro documento equivalente, ideológica o materialmente falsos”. 


\section{FUNDAMENTACIONES DE LA CAUSA JUDICIAL SOBRE LA PARTICIPACIÓN NECESARIA DEL CONTADOR PARA LA OCURRENCIA DEL DELITO DE EVASION}

\subsection{Fundamentaciones de los jueces y del organismo de control fiscal.}

La lectura de los fundamentos permite tomar conocimiento y razón de ciertos aspectos relevantes, relacionados a tareas inherentes a la práctica contable y de auditoría, que los jueces han tenido en cuenta al momento de dictar resolución condenatoria, y ante la consumación del delito de evasión en el marco de la ley penal tributaria. Transcribimos algunas:

* “....Los trabajos contables que realizó el contador lo colocan realizando un especial aporte técnico, exclusivamente para facilitar la comisión del delito previsto en el art. $1^{o}$ de la ley penal tributaria, por lo que según esa norma le corresponde penas por su participación criminal en esos hechos, más la pena de inhabilitación especial por el doble de tiempo de la condena. Agregó el juez que del análisis probatorio surge que para confeccionar las declaraciones juradas engañosas fue necesario la contribución del contador de la empresa...” (folio 1026 vuelta - expediente de la causa)."

* “...Si tenemos en cuenta que la evasión consiste en inducir a engaño al ente fiscalizador, para pagar menos impuesto del debido, el balance confeccionado falsamente, que permite ocultar la verdadera ganancia de la empresa, es un medio idóneo, para conseguir el fin deseado, porque ello induce a engaño al ente fiscalizador, máxime cuando cumple con los recaudos legales, entre los que se encuentra como fundamental la certificación de un profesional de ciencias económicas. En esas condiciones, la intervención como partícipe del contador fue primaria, pues de no contar con su colaboración en la certificación del balance, éste no podría haber sido utilizado para respaldar, falsamente, menores ganancias de las realmente obtenidas..."(Marconi,2005,p.74-79) (folio 1027 - expediente de la causa).

Por su parte, el juez doctor Guillermo J. Yacobucci ${ }^{9}$ argumentó que el tribunal oral acreditó fehacientemente la participación del contador en el hecho delictivo a través de su aporte técnico, y se ciñó a las reglas de la sana crítica racional, valorando acertadamente las pruebas obrantes en el juicio y concluyendo que su intervención fue penalmente relevante. Se entiende por reglas de la sana crítica racional una apreciación de la prueba, por parte del juez, atendiendo a la lógica aplicable al caso, su experiencia y a sus conocimientos afianzados.

\footnotetext{
${ }^{8}$ Expresiones en el registro № 15.654 del Señor Juez Doctor W. Gustavo Mitchell Presidente integrante de la Sala II de la Cámara Nacional de Casación Penal resolución recurso interpuesto contra la resolución de fs.996/1030 de la causa № 9950 de Sala II caratulada "Krochik, Sebastián y otros/ Recurso de casación."

${ }^{9}$ Vocal integrante de la Sala II de la Cámara Nacional de Casación Penal en resolución recurso interpuesto contra la resolución de fs.996/1030 de la causa № 9950 de Sala Il caratulada "Krochik, Sebas-tián y otros/ Recurso de casación."
} 
Por su parte, el juez Luis M. García, otro vocal de la Cámara Nacional de Casación, dijo que "...quedó acreditado, más allá de toda duda, que la registración contable y las declaraciones juradas fueron confeccionadas bajo la exclusiva responsabilidad del contador B, lo que lo transforma en partícipe necesario de la conducta que se le enrostró al presidente de la firma obligada al pago de los tributos. Es que cada acto parcial que realizó el contador B. posee la característica de ser autónomo y ejecutado dentro del ámbito de responsabilidad del sujeto que lo realiza, tuvo la posibilidad de elegir entre plantearlos legalmente o pergeñar esas maniobras engañosas, que en definitiva ejecutó, en el marco de una diversificación de funciones pre y coordenadas, por lo tanto esos actos ejecutados individualmente tienen relevancia jurídico penal y fueron realizados sabiendo que el plan que había dispuesto el presidente de la firma 'K. S.A.' era evadir...." (folio 1025 vuelta - expediente de la causa).

Por su parte la AFIP, como parte litigante en esta causa, manifestó que el contador J.R.B. "...no era un simple auditor externo ya que su esfera de dominio social era significativa al poseer los libros de la firma, contenía claves y aplicativos para la presentación de las declaraciones juradas frente a la Administración federal de ingresos públicos, había comenzado a trabajar con la firma desde que empezó a operar comercialmente la misma, calificando el propio presidente de la firma que el contador J.R.B. manejaba la parte impositiva". Agregó que el contador hasta se encuentra en una posición de garante frente al bien jurídico protegido por sus conocimientos especiales, como lo entendió el legislador al imponer un plus de pena en el art. 15 inc. "a" de la ley 24.769 (artículo que no sufrió modificaciones con la ley 26.735 BO: 28-12-2011).

Esta argumentación del organismo de control merece un análisis más detallado, ya que se refiere a algunos aspectos críticos que forman parte del actual modus operando de la mayoría de los estudios contables, respecto a la forma en que materializan la prestación de sus servicios, al amparo de la visión judicial y cobrando particular relevancia ya que puede influir en forma negativa al momento de calificar una conducta profesional, por parte de los jueces. A nuestro criterio, los siguientes párrafos que se transcriben merecen una atención especial por los términos utilizados:

1.- "...no era un simple auditor externo ya que su esfera de dominio social era significativa al poseer los libros de la firma, contenía claves y aplicativos para la presentación de las declaraciones juradas frente a la Administración federal de ingresos públicos...” De una simple lectura, podría interpretarse una visión confusa, en cuanto la tarea a desarrollar por el auditor externo. Deja ver una idea y concepto de connivencia y conductas no acordes con los niveles de los auditores externos, en cuanto su esfera de actuación, conocimiento y dominio en la empresa.

Esto plantea los siguientes interrogantes... ¿qqué significa ser un simple auditor externo?... ¿̇tiene implícita una clasificación antagónica de auditor externo simple y especial?...

La mención a que el auditor posee "...los libros de la Firma, las claves fiscales y los apli- 
cativos de las declaraciones juradas impositivas...”, está ligada a la actuación del auditor en un contexto en el que la normativa profesional permite brindar también otros servicios profesionales a un mismo cliente (liquidación de impuestos, formulación y liquidación de remuneraciones, aportes y contribuciones, asesoría contable, impositiva, organizativa, de gestión, etc.), sin que por ello, se vea afectada su independencia.

Para efectivizar la prestación de todos los servicios antes enunciados, generalmente, por una cuestión de organización y para ofrecer un servicio razonablemente eficiente y completo, el estudio profesional, se encarga del envío de las declaraciones juradas, para lo que necesita la clave fiscal; encargándose, en algunos casos, hasta del trámite del pago de los tributos, asumiendo así, las tareas inherentes a todo el circuito de prestación del servicio. Prueba de ello se evidencia en la expresión utilizada “...calificando el propio presidente de la firma que el contador J. R. B. manejaba la parte impositiva...”, planteándonos otros interrogantes a los antes formulados... ¿qué quiso decir el presidente de la empresa con la expresión manejaba? ¿qué entenderá la AFIP por ese término?.

El contador realiza las liquidaciones impositivas sobre la documentación que el contribuyente brinda, siendo siempre el contribuyente el responsable de la integridad de la documentación que entrega y del contenido de la declaración jurada (impositiva, previsional, de ingresos, etc.) que corresponde a cada actividad económica del contribuyente.

El actual ejercicio de la profesión plantea situaciones que pueden presentarse confusas como las descriptas, especialmente aquellas que requieren de la clave fiscal del contribuyente, y en las que el contador -conociendo dicha clave- la utiliza para realizar algún trámite, por ejemplo, en el caso de las declaraciones juradas impositivas que son procesadas y enviadas desde la computadora del propio Estudio contable.

En este escenario, cobra importancia la previsión de ciertos aspectos de forma en la prestación de los servicios profesionales; la celebración de un convenio de servicios profesionales, en los que se detallan claramente el alcance de los servicios a prestar y el carácter de los mismos, no debería omitirse bajo ningún concepto, sea cual fuere el tipo de servicio profesional que se pacte.

2.- "...y hasta se encuentra en una posición de garante frente al bien jurídico protegido "por sus conocimientos especiales", como lo entendió el legislador al imponer un plus de pena en el art. 15 inc. " $a$ " de la ley 24.769...". Antes de profundizar en el significado de estas expresiones, recordemos que el bien jurídico protegido se refiere, en general, al patrimonio de la administración pública, cualquiera sean los poderes del Estado (Nacional, Provincial o Municipal).

La jurisprudencia, algunos jueces y la AFIP ubican al profesional en ciencias económicas en una posición estratégica, por sus conocimientos y preparación, elevándolo al nivel de garante del bien jurídico protegido, lo que nos exige reflexionar sobre la responsabilidad que tenemos y que debemos asumir en la práctica laboral, en un contexto legal y profesional sumamente complejo, 
cada vez más comprometido, y crecientemente sobre exigido a la luz de los acontecimientos crecientes en el ámbito político, económico, financiero, con aristas en la faz penal.

El delito de evasión, según se encuentra tipificado en nuestro sistema legal, no es un delito de pura infracción del deber porque requiere, al momento de su ejecución, de comportamientos engañosos, tanto de simulación como de ocultamiento; y es por eso que se ejecutan a través de determinadas formas de organización o dominio que trascienden el simple incumplimiento, además de producir un daño patrimonial al Estado. Es decir, la evasión no se constituye por la mera omisión del deber de informar y pagar las obligaciones tributarias o previsionales, sino que debe acontecer en un marco de organización descripto como engañoso y con perjuicio patrimonial, simultáneamente.

En este marco, los jueces de la causa consideraron que el aporte del contador de la empresa autora del delito se integra en ese ámbito, y que se concreta en un comportamiento engañoso del obligado, y no en el solo hecho de no cumplir con el pago de los tributos.

También se tiene en cuenta que el contador se encuentra vinculado con la empresa desde el año 1995, confeccionando anualmente el balance, su análisis y el "dictamen o juicio de probabilidad (sic)". De aquí la imputación referente al artículo 15 de la Ley 24769.

De la lectura de la argumentación de los jueces de la causa que se está examinando, llama la atención que utilizan, reiteradamente, la expresión dictamen o juicio de probabilidad, cuando este último término no surge del ámbito profesional. Se puede suponer que se refiere a la opinión que emite el auditor de los estados contables de un ente sobre la razonabilidad o no de la información contenida en ellos, de acuerdo a las normas contables profesionales vigentes, con la aclaración de que también el auditor puede abstenerse de emitir su opinión.

\subsection{Fundamentaciones de la defensa del contador público imputado.}

La defensa del contador manifestó “...que las registraciones contables y las declaraciones juradas no fueron confeccionadas por sus propias manos y que su contenido son de absoluta responsabilidad de los directivos de la empresa”.

En esta línea, los jueces señalan que el contador, como sujeto competente, a través de un dominio del hecho, desenvolvió un aporte esencial para las maniobras de evasión y que no resulta un obstáculo para la imputación, el hecho de que no hubiere ejecutado de propia mano determinadas tareas.

Se trata de identificar sobre quien recae el deber profesional, careciendo de significación la identificación de las personas que materialmente realicen las declaraciones juradas, puesto que, jurídicamente, la confección de ellas es efectuada bajo el control de un Contador público, dentro del ámbito de competencia de dicho profesional, que ejerce una función reglada de naturaleza normativa.

Aquí adquiere importancia el rol asumido por el contador y las consecuencias que surgen de su ejercicio profesional con el objeto de facilitar el delito especial cometido por un directivo de la empresa obligada al pago de los tributos evadidos. 


\section{CONCLUSIONES Y SUGERENCIAS}

El recorrido literal, la revisión conceptual y el somero análisis realizado, exterioriza múltiples indicios y señales de alerta para el contador público, de modo muy especial, cuando son contratados y se prestan servicios de auditoría externa que nos permiten arribar a las siguientes conclusiones:

* Los jueces -a tenor de sus fallos- mayormente entienden que:

* El contador público realiza un especial aporte técnico tendiente a facilitar la comisión del delito de evasión fiscal por parte de las empresas a las que presta servicios profesionales (artículo $1^{\mathrm{o}}$ de la ley penal tributaria).

* La participación del contador público en la confección de declaraciones juradas impositivas y previsionales engañosas es necesaria.

* El contador público, como sujeto competente y, a través de un dominio del hecho, desenvuelve un aporte esencial para las maniobras de evasión, y que, el hecho de no ejecutar de propia mano determinadas tareas, no resulta un obstáculo para la imputación, porque lo que se trata es de identificar sobre quien recae el deber profesional.

* Los jueces, en sus considerandos como así también en sus fallos, pueden sostener que las registraciones contables y las declaraciones juradas impositivas o previsionales, son confeccionadas bajo la exclusiva responsabilidad del contador público, y así transformar al profesional en partícipe necesario de la conducta delictiva, considerando que los actos llevados a cabo por el contador poseen la característica de ser autónomos y ejecutados dentro del ámbito de responsabilidad del sujeto que lo realiza, y que él tiene la posibilidad de elegir entre plantearlos legalmente o contribuir a la realización de maniobras engañosas.

* Cuando una empresa incurre en el delito de evasión por presentación de una declaración jurada engañosa, en la que se determina un importe menor de impuesto a pagar; calculada sobre la base de estados contables auditados previamente, la participación del auditor externo en un momento previo al de la ocurrencia del hecho delictivo (confección de la declaración jurada de ganancias), no sirve de atenuante para la condena al profesional como partícipe necesario en ese delito.

* El contador debería tener un conocimiento general del ente al que presta sus servicios, que le permita identificar los factores de riesgo que vislumbren indicios de conductas y actitudes del contribuyente propensas a la evasión.

* El contador debe tener especial cuidado al momento de obtener un poder (del tipo que fuere), para actuar o representar a su cliente, porque la justicia, a los efectos de demostrar su vinculación con una empresa autora del delito de evasión fiscal, puede tener en cuenta 
dicho poder, entendiendo que fue él quien tomó determinadas decisiones de raigambre delictiva, comprometiendo su actuación meramente profesional.

* La existencia de un convenio, acuerdo o contrato de servicios profesionales, en el que se definan los términos de la relación y actuación profesional, será siempre clave al momento de probar el alcance de los servicios y responsabilidad profesionales, en caso de algún conflicto. Así también, la confección y guarda de papeles de trabajo adecuados, se convierte en una documentación relevante y probatoria para estos casos.

* En la mayoría de los casos, tratándose de un incumplimiento de las obligaciones tributarias o previsionales por parte de la sociedad (ente de existencia ideal), materializado en el no pago de determinados impuestos o los aportes y contribuciones de la seguridad social, resulta dable aceptar que no puede el síndico desconocer dicho incumplimiento ante el fisco, por las tareas inherentes a esa función.

* La responsabilidad puede surgir por comisión u omisión, de allí que el desempeño profesional, en cualquier área, exige del cuidado y competencia para brindar servicios de alta calidad.

\section{REFERENCIAS BIBLIOGRÁFICAS}

Gil, J. (2008, julio) ¿Qué normas exigen que los estados contables de las sociedades deben estar con informe de auditoría? Imagen Profesional (67), p.33.

Marconi, N.J. (2005, julio) Práctica Profesional Tributaria, Laboral y de la Seguridad Social (7/05), p. 74/79.

Mosset Iturraspe, J. y González Zünd,R.A. (2014) Responsabilidad civil de los Profesionales Abogados, Contadores, Auditores. Chaco: Contexto Editorial.

Trigo Represas, F.A. y López Mesa ,M.J. (2004) Tratado de la responsabilidad civil Tomo I Buenos Aires: Editorial La Ley.

Valleta (2006) Diccionario jurídico (4º edición). Valleta Buenos Aires: ediciones SRL. Pág. 688.

\section{Material legal y normativo}

* Ley 11.683 - Procedimiento fiscales - Parte Pertinente.

* Ley 24.769 - Ley Penal Tributaria y Previsional y su modificatoria - Ley 26.735. 
* Memorando Técnico de la FACPCE sobre Responsabilidad del contador público que actúa como auditor, síndico societario, consultor o asesor técnico impositivo o provisional, liquidador impositivo, o que presta servicios de tercerización (llevar la contabilidad, liquidación de sueldos y otros).

* Resolución conjunta de la FACPCE y de la Federación Argentina de Graduados en Ciencias Económicas sobre "funciones y responsabilidades del contador público".

* Resolución Técnica (FACPCE) No 15 - Normas sobre Actuación del contador público como auditor y síndico societario.

* Resolución Técnica (FACPCE) No 37 - Normas de auditoría, revisión, otros encargos de aseguramiento, certificación y servicios relacionados.

\section{CURRICULUM VITAE Rossana Greco}

Contadora Pública egresada de la Facultad de Ciencias Económicas de la Universidad Nacional del Nordeste - UNNE (Año 1989). Especialista en Contabilidad Superior y Auditoría (2007) y Especialista en Docencia Universitaria (2011).

Docente por concurso en las Asignaturas Auditoría (desde 2002) y Estados Contables (desde 2004) de la Carrera de Contador público de la Facultad de Ciencias Económicas. UNNE. Investigadora categorizada.

Docente en Posgrados dictados en la Universidad Nacional del Nordeste (UNNE), Universidad Nacional de Misiones (UNAM), Universidad Nacional de La Plata (UNLP), Universidad Nacional de Mar del Plata (UNMDP) y en la Universidad Nacional de Asunción Paraguay (UNA).

Egresada del V Programa de Formación de Formadores en Responsabilidad Social Empresaria (2011) organizado por la Red Iberoamericana de Universidades por la RSE (REDUNIRSE). Expositora y Autora de artículos publicados en Revistas especializadas.

Miembro titular del Instituto de Ciencias Jurídicas y Sociales en la región Nordeste de la Academia Nacional de Derecho y Ciencias Sociales de Córdoba.

\section{rgreco@eco.unne.edu.ar}

\section{Oscar Nedel}

Contador público egresado de la Facultad de Ciencias Económicas de la Universidad Nacional del Nordeste. Especialista en Sindicatura Concursal y en Administración de Empresas en Crisis. Abogado y Procurador. Profesor Titular de la asignatura Práctica Profesional de la carrera de Contador público de la Facultad de Ciencias Económicas. UNNE.

Docente en Carreras de Posgrado de la Universidad Nacional del Nordeste (UNNE), Universidad Nacional de Misiones (UNAM), Universidad Nacional de Formosa (UNAF) y en la Universidad Nacional de Entre Ríos (UNER).

Expositor, Disertante y Autor de artículos sobre temas de la práctica profesional publicados en Revistas especializadas. 
Autor de veinte (20) Libros de uso Académico y Profesional sobre temas de la práctica del Profesional en Ciencias Económicas y otros temas relacionados.

Miembro adherente a la Asociación Interamericana de Contabilidad (AIC).

Actuación Profesional autónoma. Titular de Estudio propio, con actuación profesional en las Provincias de Santa Fe, Misiones, Corrientes, Formosa y Chaco.

ene-oscar@gigared.com 